\section{Healthy Vision Month — May 2019}

May is Healthy Vision Month, an annual observance dedicated to making vision and eye health a national priority. During this month, CDC's Vision Health Initiative (VHI) in the Division of Diabetes Translation joins with the National Eye Institute's National Eye Health Education Program to educate the public about preventing vision loss and promoting eye health. Almost 3.22 million U.S. persons are affected by vision impairment, which can be associated with social isolation, disability, and decreased quality of life (https://www.cdc.gov/visionhealth/risk/ burden.htm).

In this issue of $M M W R$, VHI staff members report findings from their study examining the association of vision impairment and functional limitations related to subjective cognitive decline (SCD), defined as the experience of worsening or more frequent confusion or memory loss (1). Analysis of data from the Behavioral Risk Factor Surveillance System survey for the years 2015-2017 indicated that persons with vision impairment were 3.5 times more likely to report functional limitations related to SCD than were those with no vision impairment.

With the number of U.S. adults with vision impairment projected to double in the next 30 years (2), understanding the impact of comorbid vision and SCD on functioning is just one of many important public health concerns related to vision loss. For information on topics related to vision and eye health, including common eye disorders, prevention, and related state and community programs, please visit the VHI web page (https://www.cdc.gov/visionhealth).

\section{References}

1. Saydah S, Gerzoff RB, Taylor CA, Ehrlich JR, Saaddine J. Vision impairment and subjective cognitive decline-related functional limitations-United States, 2015-2017. MMWR Morb Mortal Wkly Rep 2019;68:453-7.

2. Chan T, Friedman DS, Bradley C, Massof R. Estimates of incidence and prevalence of visual impairment, low vision, and blindness in the United States. JAMA Ophthalmol 2018;136:12-9. https://doi. org/10.1001/jamaophthalmol.2017.4655

\section{Vision Impairment and Subjective Cognitive Decline-Related Functional Limitations - United States, 2015-2017}

Sharon Saydah, $\mathrm{PhD}^{1}$; Robert B. Gerzoff, $\mathrm{MS}^{1}$; Christopher A. Taylor, $\mathrm{PhD}^{2}$; Joshua R. Ehrlich, $\mathrm{MD}^{3}$; Jinan Saaddine, MD, $\mathrm{PhD}^{1}$

Vision impairment affects approximately 3.22 million persons in the United States and is associated with social isolation, disability, and decreased quality of life (1). Cognitive decline is more common in adults with vision impairment $(2,3)$. Subjective cognitive decline (SCD), which is the selfreported experience of worsening or more frequent confusion or memory loss within the past 12 months, affects $11.2 \%$ of adults aged $\geq 45$ years in the United States (4). One consequence of SCD is the occurrence of functional limitations, especially those related to usual daily activities; however, it is not known whether persons with vision impairment are more likely to have functional limitations related to SCD (4). This report describes the association of vision impairment and SCD-related functional limitations using Behavioral Risk Factor Surveillance System (BRFSS) surveys for the years 2015-2017. Adjusting for age group, sex, race/ethnicity,

\section{INSIDE}

458 Progress Toward Polio Eradication - Worldwide, January 2017-March 2019

463 Notes from the Field: Verona Integron-Encoded Metallo- $\beta$-Lactamase-Producing CarbapenemResistant Pseudomonas aeruginosa Infections in U.S. Residents Associated with Invasive Medical Procedures in Mexico, 2015-2018

466 QuickStats

Continuing Education examination available at https://www.cdc.gov/mmwr/cme/conted_info.html\#weekly.

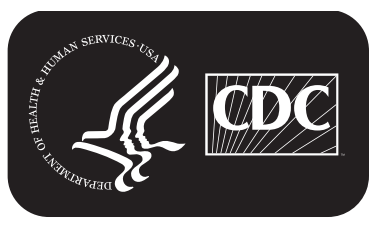

U.S. Department of Health and Human Services Centers for Disease Control and Prevention 
education level, health insurance, and smoking status, $18 \%$ of adults aged $\geq 45$ years who reported vision impairment also reported SCD-related functional limitations, compared with only $4 \%$ of those without vision impairment. Preventing, reducing, and correcting vision impairments might lead to a decrease in SCD-related functional limitations among adults in the United States.

This analysis used data from the BRFSS, an annual statebased, cross-sectional telephone survey of noninstitutionalized adults aged $\geq 18$ years, combining data from 2015, 2016, and 2017.* During those 3 years, 208,601 respondents aged $\geq 45$ years in 49 states (all except Pennsylvania), Puerto Rico, and the District of Columbia (DC) completed the optional cognitive decline module. ${ }^{\dagger, \Phi, \boldsymbol{\Phi}}$ For states that administered the module in multiple years, only the most recent year's data were included. For the BRFSS surveys in 2015, 2016, and 2017, the combined landline and cellular telephone response rates among states, Puerto Rico, and DC ranged from $30.6 \%$ to 64.1\% (median $=45.7 \%)$.

Among all respondents aged $\geq 45$ years, those classified as having SCD responded affirmatively to the question "During the past 12 months, have you experienced confusion or memory loss that is happening more often or is

\footnotetext{
*https://www.cdc.gov/brfss.

$\dagger^{\dagger}$ https://www.cdc.gov/brfss/annual_data/2015/pdf/2015-sdqr.pdf.

${ }^{\$}$ https://www.cdc.gov/brfss/annual_data/2016/pdf/2016-sdqr.pdf.

'https://www.cdc.gov/brfss/annual_data/annual_2017.html.
}

getting worse?" Respondents with SCD were then asked two follow-up questions: 1) "During the past 12 months, as a result of confusion or memory loss, how often have you given up day-to-day household activities or chores you used to do, such as cooking, cleaning, taking medications, driving, or paying bills?" and 2) "During the past 12 months, how often has confusion or memory loss interfered with your ability to work, volunteer, or engage in social activities outside the home?" Responses of "always," "usually," and "sometimes" were classified as positive responses, and responses of "rarely" and "never" were classified as negative responses (4). Functional limitations caused by SCD were defined as a positive response to either of the two follow-up questions. Vision impairment was defined as a yes response to the question "Are you blind or do you have serious difficulty seeing, even when wearing glasses?" Descriptive analyses examined population characteristics by vision impairment and SCD-related functional limitations status. Covariates included age group (45-64 years, 65-74 years, or $\geq 75$ years); sex (male or female); race/ethnicity (non-Hispanic white, non-Hispanic black, non-Hispanic multiracial, Hispanic, or non-Hispanic other); education level (less than high school, high school graduate or some college, or college graduate); smoking status (never, former, or current); and having health insurance (yes or no). Multivariate logistic regression models were used to calculate predicted marginal proportions and examine the relationship between vision impairment and SCD-related functional limitations, adjusting for age, sex, race/ethnicity, education level,

The MMWR series of publications is published by the Center for Surveillance, Epidemiology, and Laboratory Services, Centers for Disease Control and Prevention (CDC), U.S. Department of Health and Human Services, Atlanta, GA 30329-4027.

Suggested citation: [Author names; first three, then et al., if more than six.] [Report title]. MMWR Morb Mortal Wkly Rep 2019;68:[inclusive page numbers].

\section{Centers for Disease Control and Prevention \\ Robert R. Redfield, MD, Director \\ Anne Schuchat, MD, Principal Deputy Director \\ Chesley L. Richards, MD, MPH, Deputy Director for Public Health Science and Surveillance \\ Rebecca Bunnell, PhD, MEd, Director, Office of Science \\ Barbara Ellis, PhD, MS, Acting Director, Office of Science Quality, Office of Science \\ Michael F. Iademarco, MD, MPH, Director, Center for Surveillance, Epidemiology, and Laboratory Services}

MMWR Editorial and Production Staff (Weekly)

\begin{abstract}
Jacqueline Gindler, MD, Editor
Terisa F. Rutledge, Managing Editor Technical Writer-Editors

Matthew L. Boulton, MD, MPH Virginia A. Caine, MD

Katherine Lyon Daniel, $\mathrm{PhD}$

Jonathan E. Fielding, MD, MPH, MBA

David W. Fleming, MD

William E. Halperin, MD, DrPH, MPH
\end{abstract}

Charlotte K. Kent, PhD, MPH, Editor in Chief

Mary Dott, MD, MPH, Online Editor

Douglas W. Weatherwax, Lead Technical Writer-Editor

Glenn Damon, Soumya Dunworth, PhD, Teresa M. Hood, MS,
MMWR Editorial Board Timothy F. Jones, MD, Chairman Robin Ikeda, MD, MPH Phyllis Meadows, PhD, MSN, RN Jewel Mullen, MD, MPH, MPA Jeff Niederdeppe, $\mathrm{PhD}$ Patricia Quinlisk, MD, MPH
Martha F. Boyd, Lead Visual Information Specialist Maureen A. Leahy, Julia C. Martinroe, Stephen R. Spriggs, Tong Yang, Visual Information Specialists Quang M. Doan, MBA, Phyllis H. King, Terraye M. Starr, Moua Yang, Information Technology Specialists
Stephen C. Redd, MD

Patrick L. Remington, MD, MPH

Carlos Roig, MS, MA

William Schaffner, MD

Morgan Bobb Swanson, BS 
and smoking status. All estimates used the BRFSS-provided sampling weights to account for the complex survey design and nonresponse. Analysis was completed using SUDAAN (version 11.0.3; RTI International).

The overall prevalence of vision impairment among respondents was $6.2 \%$ (95\% confidence interval $[\mathrm{CI}]=6.0 \%-6.3 \%)$, and the overall prevalence of SCD with functional limitations was $5.5 \%(95 \% \mathrm{CI}=5.3 \%-5.7 \%)$. The prevalence of vision impairment without functional limitations related to SCD increased with age from $4.4 \%(95 \% \mathrm{CI}=4.2 \%-4.7 \%)$ among those aged $45-64$ years to $7.2 \%$ (95\% CI $=6.7 \%-7.6 \%)$ for those aged $\geq 75$ years (Table). Among adults reporting SCD-related functional limitations without vision impairment, the proportion in each of the three age groups was similar $($ range $=2.8[65-74$ years] to $4.4[45-64$ years] $)$, as was the age distribution among those with vision impairment (range $=0.9 \%$ [age 65-74 years] to 1.8 [ $45-64$ years]) . Similarly, no significant differences in report of SCD-related functional limitations among those with and without vision impairment were seen when stratified by race/ethnicity. Vision impairment without SCD related limitations was highest among Hispanics $(10.4 \%, 95 \% \mathrm{CI}=9.3-11.6)$ and lowest among non-Hispanic whites $(3.6 \%, 95 \% \mathrm{CI}=3.5 \%-3.8 \%)$. However, prevalences of vision impairment and SCD-related functional limitations were higher among adults with less than a high school diploma $(4.1 \%, 95 \% \mathrm{CI}=3.6 \%-4.6 \%)$, who were current smokers $(3.6 \%, 95 \%=3.2 \%-4.0 \%)$, and who did not have health insurance $(3.0 \%, 95 \% \mathrm{CI}=2.5 \%-3.7 \%)$ than among college graduates $(0.4 \%, 95 \% \mathrm{CI}=0.3 \%-0.4 \%)$, those who had never smoked $(0.9 \%, 95 \% \mathrm{CI}=0.8 \%-1.1 \%)$, and those who had health insurance $(1.4 \%, 95 \% \mathrm{CI}=1.3 \%-1.5 \%)$.

After adjusting for demographics, smoking status, and vision impairment, the prevalence of functional limitations related to SCD was highest among persons aged 45-64 years $(6 \%)$ and lowest among those aged $65-74$ years $(4 \% ; \mathrm{p}<0.001)$ (Figure). In addition, non-Hispanic whites and Hispanics reported the lowest prevalences (5\%), and non-Hispanic persons of other races reported the highest prevalence $(8 \%)(\mathrm{p}<0.001)$. The prevalence of SCD-related functional limitations among persons having less than a high school education (9\%) was three times that of those reporting being a college graduate $(3 \%)(p<0.001)$. Being a current smoker was associated with a higher prevalence of SCD-related functional limitations $(9 \%)$, compared with being a former smoker $(5 \%)$ or a person

TABLE. Percentage of adults aged $\geq 45$ years who reported vision impairment with and without subjective cognitive decline (SCD)-related functional limitations (FL), by selected characteristics - Behavioral Risk Factor Surveillance System, 49 states, Puerto Rico, and District of Columbia, 2015-2017

\begin{tabular}{|c|c|c|c|c|c|}
\hline \multirow[b]{2}{*}{ Characteristic } & \multicolumn{5}{|c|}{ Vision and SCD-related FL status, \% (95\% CI) } \\
\hline & Overall & $\begin{array}{l}\text { No vision impairment, } \\
\text { no SCD-related FL }\end{array}$ & $\begin{array}{l}\text { No vision impairment, } \\
\text { with SCD-related FL }\end{array}$ & $\begin{array}{l}\text { Vision impairment, } \\
\text { no SCD-related FL }\end{array}$ & $\begin{array}{l}\text { Vision impairment, } \\
\text { with SCD-related FL }\end{array}$ \\
\hline Overall & 100 & $89.7(89.4-89.9)$ & $3.9(3.8-4.1)$ & $4.9(4.7-5.1)$ & $1.5(1.4-1.6)$ \\
\hline \multicolumn{6}{|l|}{ Age group (yrs) } \\
\hline $45-64$ & $63.1(62.8-63.3)$ & $89.4(89.0-89.8)$ & $4.4(4.1-4.6)$ & $4.4(4.2-4.7)$ & $1.8(1.6-2.0)$ \\
\hline $65-74$ & $21.6(21.4-21.8)$ & $91.8(91.4-92.2)$ & $2.8(2.5-3.0)$ & $4.6(4.3-4.9)$ & $0.9(0.8-1.0)$ \\
\hline$\geq 75$ & $15.3(15.2-15.5)$ & $87.8(87.2-88.4)$ & $3.9(3.6-4.3)$ & $7.2(6.7-7.6)$ & $1.1(0.9-1.3)$ \\
\hline \multicolumn{6}{|l|}{ Sex } \\
\hline Male & $47.0(46.8-47.3)$ & $90.1(89.7-90.5)$ & $3.9(3.7-4.1)$ & $4.7(4.4-4.9)$ & $1.3(1.2-1.5)$ \\
\hline Female & $53.0(52.7-53.2)$ & $89.3(88.9-89.7)$ & $4.0(3.8-4.2)$ & $5.1(4.8-5.4)$ & $1.6(1.5-1.8)$ \\
\hline \multicolumn{6}{|l|}{ Race/Ethnicity* } \\
\hline White, non-Hispanic & $68.4(68.1-68.8)$ & 91.7 (91.4-91.9) & $3.6(3.5-3.8)$ & $3.6(3.5-3.8)$ & $1.0(0.9-1.2)$ \\
\hline Black, non-Hispanic & $10.1(9.9-10.3)$ & $85.4(84.3-86.3)$ & $4.9(4.3-5.4)$ & $7.0(6.2-7.8)$ & $2.8(2.4-3.3)$ \\
\hline Multiracial, non-Hispanic & $1.2(1.2-1.3)$ & $84.6(82.0-86.9)$ & $5.9(4.6-7.6)$ & $7.6(5.9-9.7)$ & $1.9(1.3-2.8)$ \\
\hline Hispanic & $13.9(13.6-14.2)$ & $82.2(80.8-83.6)$ & $4.5(3.9-5.2)$ & $10.4(9.3-11.6)$ & $2.9(2.3-3.5)$ \\
\hline Other, non-Hispanic & $6.4(6.1-6.6)$ & $88.8(87.1-90.3)$ & $4.4(3.6-5.4)$ & $5.0(4.0-6.2)$ & $1.8(1.2-2.7)$ \\
\hline \multicolumn{6}{|l|}{ Education level } \\
\hline Less than high school graduate & $14.7(14.4-14.9)$ & $76.5(75.3-77.7)$ & $7.3(6.7-8.0)$ & $12.1(11.1-13.1)$ & $4.1(3.6-4.6)$ \\
\hline High school graduate/Some college & $57.0(56.7-57.3)$ & $89.7(89.4-90.1)$ & $4.3(4.0-4.5)$ & $4.5(4.3-4.8)$ & $1.5(1.3-1.6)$ \\
\hline College graduate & $28.3(28.1-28.6)$ & 95.7 (95.5-95.9) & $1.7(1.6-1.9)$ & $2.2(2.1-2.4)$ & $0.4(0.3-0.4)$ \\
\hline \multicolumn{6}{|l|}{ Smoking status } \\
\hline Never smoked & $54.0(53.7-54.3)$ & $91.8(91.4-92.1)$ & $3.0(2.8-3.2)$ & $4.3(4.0-4.5)$ & $0.9(0.8-1.1)$ \\
\hline Former smoker & $31.9(31.7-32.2)$ & $90.0(89.5-90.4)$ & $3.7(3.5-4.0)$ & $4.8(4.5-5.1)$ & $1.5(1.3-1.8)$ \\
\hline Current smoker & $14.1(13.9-14.3)$ & $81.2(80.3-82.1)$ & $7.8(7.2-8.4)$ & $7.4(6.7-8.1)$ & $3.6(3.2-4.0)$ \\
\hline \multicolumn{6}{|l|}{ Health insurance status } \\
\hline Health insurance & $93.0(92.8-93.1)$ & $90.1(89.9-90.4)$ & $3.8(3.7-4.0)$ & $4.6(4.5-4.8)$ & $1.4(1.3-1.5)$ \\
\hline No health insurance & $7.0(6.9-7.2)$ & $83.2(81.6-84.7)$ & $5.3(4.5-6.3)$ & $8.5(7.3-9.8)$ & $3.0(2.5-3.7)$ \\
\hline
\end{tabular}

Abbreviation: $\mathrm{Cl}=$ confidence interval.

* Whites, blacks, multiracial, and other races/ethnicities were non-Hispanic; Hispanic persons could be of any race. 
FIGURE. Adjusted percentage* of subjective cognitive decline (SCD)-related functional limitations among adults aged $\geq 45$ years, by demographic characteristics, smoking status, and vision impairment - Behavioral Risk Factor Surveillance System, 49 states, $^{\dagger}$ Puerto Rico, and the District of Columbia, 2015-2017

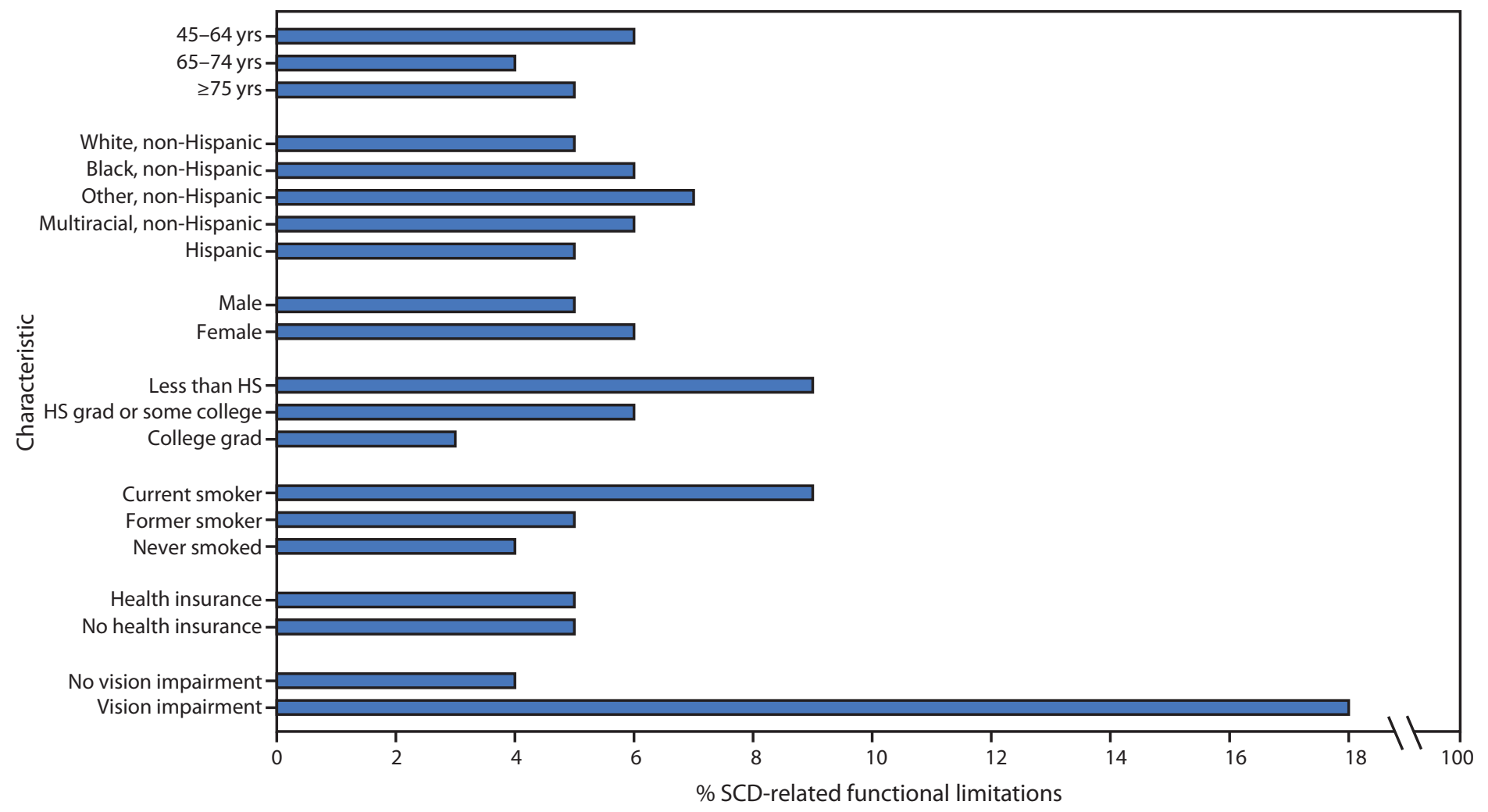

Abbreviation: $\mathrm{HS}=$ high school.

* Adjusted prevalence based on predicted marginal from logistic regression models adjusting for age, sex, race/ethnicity, smoking status, health insurance status, and vision impairment.

† Excluding Pennsylvania.

who had never smoked $(4 \%)(\mathrm{p}<0.001)$. After adjusting for demographics and smoking status, the highest prevalence of SCD-related functional limitations (18\%) was among adults with vision impairment; prevalence among those with no reported vision impairment was $4 \%(\mathrm{p}<0.001)$.

\section{Discussion}

Functional limitations have been reported by $50 \%$ of adults aged $\geq 45$ years with SCD (4), and vision impairment has been reported by $6 \%(5)$. Previous studies have determined that vision impairment and cognitive decline might co-occur (2) and might be causally related (3). Recent studies have pointed to changes in the retina as a potential biomarker for dementia (G), highlighting the link between vision impairment and cognitive decline. However, the association of vision impairment with SCD-related functional limitations has not been well characterized. This report found that among adults aged $\geq 45$ years, SCD-related functional limitations were three and one half times higher among adults with vision impairment than among those with no vision impairment. The number of adults in the United States with vision impairment is projected to double in the next 30 years (5); therefore, understanding the impact of co-occurring vision impairment and SCD on functional abilities is an important public health concern.

Vision impairment might lead to decreased quality of life, functional limitations, and an increased risk of mortality $(7,8)$. Vision impairment might prevent persons from performing instrumental activities of daily living. However, a previous study found that the relationship between vision impairment and cognitive decline might be modified by a tailored vision rehabilitation program (9). Further work can help to determine whether vision rehabilitation is also an effective strategy to improve functional limitations associated with SCD.

Vision impairment can be caused by treatable forms of vision loss such as cataracts and refractive errors, along with age-related macular degeneration, diabetic retinopathy, and glaucoma. Measures to prevent vision impairment and vision loss include receiving eye care and a comprehensive eye exam. Additional ways to protect eyes and prevent vision loss include knowing family history of eye health, eating healthy, 


\section{Summary}

What is already known about this topic?

Vision impairment often co-occurs with cognitive decline, which can be associated with functional limitations. The association between vision impairment and functional limitations related to subjective (self-reported) cognitive decline (SCD) has not been well characterized.

What is added by this report?

Analysis of 2015-2017 Behavioral Risk Factor Surveillance System data determined that, after adjusting for age and other demographic and smoking characteristics, $18 \%$ of adults who reported vision impairment also reported SCD-related functional limitations, compared with only $4 \%$ of those without vision impairment.

What are the implications for public health practice?

Prevention or correction of vision impairment might be important in in reducing functional limitations related to cognitive decline in adults aged $\geq 45$ years.

maintaining healthy weight, wearing protective eyewear, quitting or never starting smoking, washing hands before removing contact lens, and practicing workplace eye safety.

The findings in this report are subject to at least three limitations. First, these results are based on self-reported vision difficulty and SCD-related functional limitations. Objective measures of cognitive and visual functioning were not administered as part of BRFSS (4). Second, response bias might have affected the response to questions on vision impairment, SCD, and functional limitations. For example, older persons might be less likely to report SCD-related functional limitations if they consider them to be part of the aging process, thus reducing the reported prevalence of these limitations in this population. Finally, BRFSS is only administered to noninstitutionalized adults, thereby excluding those living in long-term care facilities where nearly one third of residents might have vision and cognitive impairments (10). These limitations might have biased these results toward the null hypothesis and might limit their generalizability across all populations. The strength of this analysis is that it includes nearly all states, Puerto Rico, and DC, representing 253 million U.S. adults.

Vision impairment is an important, growing public health concern in the United States (5). Adults with vision impairment might have higher levels of difficulties with activities of daily living (e.g., eating and bathing) and instrumental activities of daily living (e.g., managing finances and using a telephone) (10). Having vision impairment might increase the likelihood that persons with SCD report related functional limitations. Addressing vision impairment through prevention or corrective treatment might reduce functional SCD-associated limitations in the adult population.
Corresponding author: Sharon Saydah, ssaydah@cdc.gov, 301-458-4183.

\begin{abstract}
${ }^{1}$ Division of Diabetes Translation, National Center for Chronic Disease Prevention and Health Promotion, CDC; ${ }^{2}$ Division of Population Health, Applied Research and Translation Branch, National Center for Chronic Disease Prevention and Health Promotion, CDC; ${ }^{3}$ Department of Ophthalmology and Visual Sciences, University of Michigan, Ann Arbor, Michigan.
\end{abstract}

All authors have completed and submitted the ICMJE form for disclosure of potential conflicts of interest. No potential conflicts of interest were disclosed.

\section{References}

1. CDC. Vision Health Initiative: the burden of vision loss. Atlanta, GA: US Department of Health and Human Services, CDC; 2017. https:// www.cdc.gov/visionhealth/risk/burden.htm

2. Chen SP, Bhattacharya J, Pershing S. Association of vision loss with cognition in older adults. JAMA Ophthalmol 2017;135:963-70. https:// doi.org/10.1001/jamaophthalmol.2017.2838

3. Zheng DD, Swenor BK, Christ SL, West SK, Lam BL, Lee DJ. Longitudinal associations between visual impairment and cognitive functioning: the Salisbury Eye Evaluation Study. JAMA Ophthalmol 2018;136:989-95. https://doi.org/10.1001/jamaophthalmol.2018.2493

4. Taylor CA, Bouldin ED, McGuire LC. Subjective cognitive decline among adults aged $\geq 45$ years-United States, 2015-2016. MMWR Morb Mortal Wkly Rep 2018;67:753-7. https://doi.org/10.15585/ mmwr.mm6727a1

5. Chan T, Friedman DS, Bradley C, Massof R. Estimates of incidence and prevalence of visual impairment, low vision, and blindness in the United States. JAMA Ophthalmol 2018;136:12-9. https://doi.org/10.1001/ jamaophthalmol.2017.4655

6. Chan VTT, Sun Z, Tang S, et al. Spectral-domain OCT measurements in Alzheimer's disease: a systematic review and meta-analysis. Ophthalmology 2019;126:497-510. https://doi.org/10.1016/j. ophtha.2018.08.009

7. Christ SL, Zheng DD, Swenor BK, et al. Longitudinal relationships among visual acuity, daily functional status, and mortality: the Salisbury Eye Evaluation Study. JAMA Ophthalmol 2014;132:1400-6. https:// doi.org/10.1001/jamaophthalmol.2014.2847

8. Qiu M, Wang SY, Singh K, Lin SC. Association between visual field defects and quality of life in the United States. Ophthalmology 2014;121:733-40. https://doi.org/10.1016/j.ophtha.2013.09.043

9. Whitson HE, Whitaker D, Potter G, et al. A low-vision rehabilitation program for patients with mild cognitive deficits. JAMA Ophthalmol 2013;131:912-9. https://doi.org/10.1001/jamaophthalmol.2013.1700

10. Guthrie DM, Davidson JGS, Williams N, et al. Combined impairments in vision, hearing and cognition are associated with greater levels of functional and communication difficulties than cognitive impairment alone: analysis of interRAI data for home care and long-term care recipients in Ontario. PLoS One 2018;13:e0192971. https://doi. org/10.1371/journal.pone.0192971 